Dr Dušan Rajić,

pukovnik, dipl. inž.

Vojnotehnicki institut,

mr Božidar Žakula,

dipl. inž

dr Velibor Jovanovi c dipl. inž.

\section{UTICAJ INDUSTRIJSKE SVOJINE NA TEHNICKO-TEHNOLOŠKI FAKTOR ODBRANE}

UDC: $347.77: 623.483$

Rezime:

U radu je analiziran uticaj industrijke svojine na tehnicko-tehnološki faktor odbrane. Tehnoloske inovacije predstavljaju znacajnu pokretacku snagu privrednog razvoja zemlje i njene odbrambene industrije. Ukazano je na potrebu drugacijeg organizovanja u oblasti inovacione delatnosti u kojoj je uspostavljena tesna veza izmedu nauke, pronalazaštva i proizvodnje.

Ključne reči: inovacije, patenti, intelektualna svojina, vojna industrija, odbrana.

\title{
THE INFLUENCE OF INDUSTRIAL PROPERTY ON THE
} TECHNICAL-TECHNOLOGICAL FACTOR OF DEFENCE

Summary:

The influence of industrial property on the technical-technological factor of defense is analyzed in this work. Technical innovations represent an important fore of business development of the county and its defensive industry. In this work it is pointed out the necessity for different way of organization in the field of innovative work in which the tight connections are established between science, innovation and production.

Key words: innovations, patents, intellectual property, military industry, defense.

\section{Uvod}

Nekada se trgovalo proizvodima tzv. niske tehnologije, koji su zadovoljavali primarne ljudske potrebe za ishranom, ode vanjem, itd. Danas vecina proizvoda, pa cak i potrošna roba, sadrži udeo pronalazaka i dizajna, zbog cega ima vecu vrednost, odnosno cenu. Filmovi, zvuc ni zapisi, knjige, kompjuterski softver, sredstva naoružanja i vojne opreme (NVO) i drugi proizvodi na tržištu, kupuju se i prodaju zbog informacija i kreativnosti koje sadrže, a ne samo zbog materijala od kojih su sacinje ni.

Svi proizvodi s kojima danas dolazimo u dodir tekovine su necijeg stvaralaštva, u tehnickom, dizajnerskom i u autor- skom smislu, kao proizvod odredenog tradicionalnog znanja nacionalne kulture $\mathrm{s}$ odredenog geografskog podrucja i dr. Drugim recima, to je necija intelektualna svojina - poje dinca, grupe autora ili na roda.

U svim zemljama u sve tu autorima je dato pravo da sprece druge da bez nadoknade koriste njihove pronalaske, dizajn ili druge vrste stvaralaštva. Ovo pravo naziva se pravo intelektualne svojine.

Intelektualna svojina je najskuplja roba na sve tu, jer je za nju neophodno vrhunsko znanje, koje ima veoma visoku cenu na tržištu. Tako npr. više vredi gram enzima butirilholinesteraze, koji proizvodi naš Vojnotehnic ki institut za potrebe detekcije visokotoksic nih he mijskih materija, od grama zlata. Danas se 
vode pravi trgovinski ratovi izmedu zemalja, kada neka od njih proceni da su joj prava u pogle du intelektualne svojine ugrožena (npr. SAD - Kina). Znacaj intelektualne svojine može da se proceni i po tome što se u okviru pregovora za ulazak u razne evropske ili svetske asocijacije, poput Evropske unije, Svetske trgovinske organizacije i dr., kao je dan od najvažnijih uslova koji neka ze mlja mora da is puni, postavlja pitanje adekvatnog rešavanja prava iz te obla sti [1].

Najrazvijenije zemlje, poput SAD, ostvaruju prihode od izvoza autorskih prava (tzv. kopirajt prihodi) u iznosu od $60 \%$ od ukupnog izvoza [1]. U Japanu 284 firme ostva ruju 45\% svojih prihoda, iskljucivo primenom znanja $i$ novih ideja. Za razvijene zemlje izvoz znanja, tj. ideja i kreativnosti, najjednostavniji je izvoz koji donosi najvece prihode.

U srednje razvije nim i nerazvijenim zemlja ma izvoz znanja i kreativnosti je veoma mali, a uvoz veliki. Tako je na primer, u Argentini izvoz znanja svega 4-5\% od ukupnog izvoza ove zemlje. Slic na je situacija i sa ostalim srednje razvije nim i nerazvijenim zemlja ma, pa i sa našom [1].

$\mathrm{Za}$ vojnu industriju karakteristican je poseban društveni status zbog strogih zahteva u obla sti kvaliteta proizvoda, posebnih mera u proizvodnji i prometu NVO, ali i visoke profitabilnosti. Na dinamican razvoj vojne industrije u svetu znatan uticaj ima uvodenje sistema zaštite proizvoda i postupaka za nje govo dobijanje i primenu (patentni sistem), sistema koji obezbeduje monopol i vracanje, u dovoljno dugom periodu, izuzetno visokih uloženih sredstava u is traživanja i razvoj NVO.
Vojna industrija Srbije uspešno se razvijala u periodu posle Drugog svetskog rata, kada je u visokom stepenu pokrivala glavne potrebe naše vojske $\mathrm{i}$ ostvarivala respektabilan izvoz. Medutim, od de vedesetih godina prošlog veka, tj. od perioda raspada bivše države, došlo je do dezintegracije je dinstve ne vojne industrije i njenog ula ženja u period kontinuirane stagnacije.

Poznato je da tehnološke inovacije mogu da budu zamajac ubrzanog razvoja privrede, ali i nje nog oporavka, tako da sadašnji „bolan“ period tranzicije kroz koji prolazi naša privreda, a sa njom i odbrambena industrija, predstavlja priliku i potrebu za uvodenje efikasnijeg modela poslovanja, za snovanog i na tzv. inovacionom modelu. $\mathrm{U}$ tom smislu, u radu se ukazuje na mogucnosti boljeg organizovanja, povezivanja i osmišlje nijeg pristupa u obla sti inovacione delatnosti u nas.

\section{Pojam i karak teristike intelektualne svojine}

Pod pojmom intelektualne svojine podrazume vaju se prava industrijske svojine i autor ska prava. Predmet zaštite prava intelektualne svojine su duhovne tvorevine i pravo autora na rezultate svog intelektualnog stva ralaštva [2].

Industrijska svojina, kao deo intelektualne svojine, najcešce se deli na dve obla sti [3]. To su:

1. Zaštita znakova razlikovanja, posebno žigova i geografskih oznaka porekla. Zaštita takvih znakova razlikovanja ima za cilj da stimuliše i osigura lojalnu konkurenciju i da zaštiti potrošace, dajuci im pravo izbora na osnovu pune informa- 
cije izmedu raznih roba i usluga [4]. Zaštita može trajati neograniceno, ukoliko odredeni znak i dalje ispunjava uslove za zaštitu. „Coca Cola“ ce pre dati svoje fabrike i tehnologiju ne go svoj žig. U mnogim slu cajevima to je najveci kapital. Interesantno je da se u našoj ze mlji od 1921. godine stalno održava 31 strani žig, poput Dunlop gume, Mauzer (oružje), Mercedes, Monblan (pera za pisanje), Remington (pisace mašine), Sidol (sredstva za cišcenje), Žilet (nožic i pribor za brija nje), Singer (šivace mašine) i dr. Dakle, za potrošaca nije svejedno da li kupuje kompjutersku opremu cuvene firme Hewlett Packard ili neke neafirmisane firme na tržištu. Jasno je da je u prvom slu caju rizik od pogrešne kupovine znacajno manji.

2. Pronalasci koji se štite patentom i malim patentom, industrijski modeli $\mathrm{i}$ uzorci, cija je osnovna svrha da obezbede zaštitu ula ganja u razvoj novih tehnologija. Ova vrsta industrijske svojine prevashodno se štiti da bi se stimulisalo stvaranje inovacija, dizajna i tehnološ ko stvaralaštvo. Zaštita se obic no daje na odredeno vreme (najcešce 20 godina u slucaju patenta). Kada se ovi oblici intelektualnog stvaralaštva ne bi štitili, prestao bi interes za ula ganje ogromnih sredstava u razvoj novih tehnologija, us porio bi se tehnološki razvoj, što nikome nije u interesu.

Nisu sve vrste intelektualnih dobara pronalasci. To nisu, na primer, naucna otkrica, naucne te orije, matematic ke metode, estetske kreacije, pla novi, pravila i postupci za obavlja nje intelektualne delatnosti, igranje igara, racunarski programi (izuzetak je patentno zakonodavstvo SAD-a) i prikazivanje informacija definisanih njihovim sadržajem [2, 3].
Suština razlikovanja pronalaska od otkrica le ži u cinjenici da je pronalazak primenje no znanje koje predstavlja materijalizaciju ideje, tj. znanje koje se koristi radi zadovoljenja odredene objektivne ljudske potrebe, dok je otkrice cisto (neprimenje no) znanje [3]. Dakle, razlog zbog kojeg patentno pravo iskljucuje otkrica iz zaštite nije u kvalitetu novosti koje to znanje ima, ili u shvatanju da je intelektualni rad koji je potreban za otkrice manji od onog koji je potreban za pronalazak, vec u pravno-politickom stavu koji se tice obima zaštite i nje nih društvenih posle dica. Interesantno je da Nikolu Teslu mnogi sma traju našim naj vecim na ucnikom. Me dutim, po opšte prihvacenim svetskim kriterijumima vrednovanja naucnog doprinosa (broj objavlje nih radova, impact faktor casopisa, indeks citiranosti i dr.) naš najveci naucnik je Milutin Milankovic, dok je Nikola Tesla naš najveci pronala zac. Ma da, veliki nauc nici cesto su bili i veliki pronalazaci (npr. Mihailo Pupin).

Patentna zaštita za otkrica bi, s obzirom na opšti karakter svog predmeta, imala nesagle divo širok obim. To bi svima, izuzev nosiocu patenta, one mogucilo slobodu korišcenja otkrica za konkretne praktic ne primene, što je sa stanovišta razvojnih interesa društva ne prihvatljivo. $S$ druge strane, patentna zaštita za pronalazak (kao znanje koje je ograniceno na konkretnu praktic nu primenu), ima je dan sasvim odredeni i ograniceni obim, što se sa stanovišta društvenog interesa smatra poželjnim, tj. stimulativnim za tehnicko stvaralaštvo. Odnos izmedu otkrica i pronala ska može se posmatrati i u svetlu ci njenice da pronala sku prethode opšta znanja koja su rezultat otkrica. Medutim, mo- 
že se desiti da otkrice i pronalazak koincidiraju, tj. da se do otkrica dode upravo kroz prakticnu primenu dotad nepoznate prirodne zakonitosti koja postoji izmedu odredenih poja va. Za patentnopravne in terese lica znacajan može biti redosled kojim ce se obja viti rezultati. U vezi s tim, moguce su dve tipic ne situacije:

1. Jedno lice otkrije odredenu supstancu u prirodi, pa, upoznavši nje nu strukturu i svojstva, sintetiše takvu istu supstancu. Racionalno bi bilo da to lice ne objavljuje svoje otkrice vec da samo prija vi svoj pronalazak za patentiranje. $U$ suprotnom, patentiranje pronalaska ne bi bilo moguce, jer supstanca na koju se pronalazak odnosi ne bi bila nova. Opisani slucaj je kod nas veoma cest, jer su autori otkrica u velikom broju slucajeva po profesiji naucni radnici koji imaju obavezu da publikuju svoje radove u naucnim casopisima, kako bi, sagla sno tome, mogli u strucnom pogle du da napreduju. Dakle, u pitanju je nepravilan redosled poteza koji može da prouzrokuje ozbiljnu štetu, a o kojem naucni radnici u

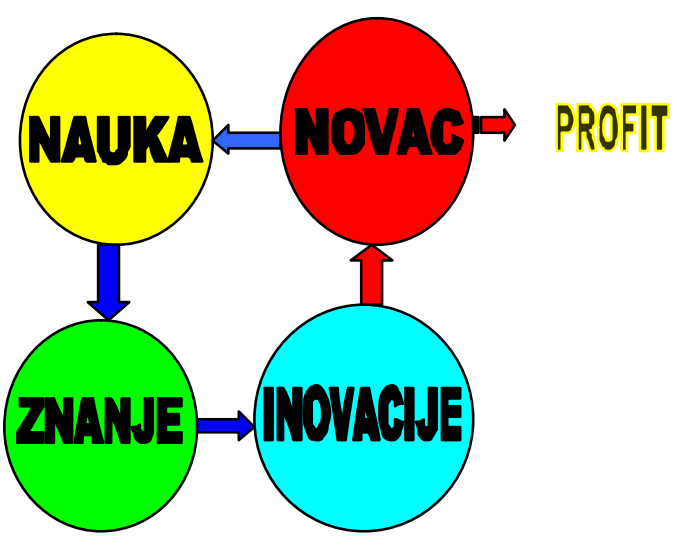

Sl. 1 - Šematski prikaz ciklusa potrošnje novca u naucne svrhe zbog stvaranja znanja i korišcenje tog znanja za stvaranje inovacija koje na tržištu donose ekstraprofit
Vojsci Srbije, i u gradanstvu jednostavno nisu oba vešteni. U razvijenom sve tu veoma se retko dogada da se patentibilni rezultati publikuju u casopisima pre ne go što se podnesu patentne prija ve.

2. Jedno lice otkrije odredenu prirodnu zakonitost i odmah pronade nacin praktic ne primene tog otkrica. Problem koji se pri patentiranju takvog pronala ska može ja viti, ukoliko to lice pre patentne prija ve objavi svoje otkrice, je ste što se može is postaviti da pronalazak ne ma inventivni nivo. Drugim recima, moguce je da takav pronalazak za struc nja ka proizlazi iz samog otkrica na nacin da nikakav inventivan rad nije neophodan. Zato je uputno da pronalazac prvo prijavi svoj pronalazak za patentiranje, a da tek zatim (odnosno tek u patentnoj prijavi) objavi otkrice koje se nalazi u osnovi tog pronalaska.

Ovi primeri pokazuju da je nauka u uskoj vezi sa pronalazaštvom, ali da istovremeno postoje brojne suštinske razlike izmedu ova dva pojma. Tako se, na primer, patentno pravo zadovoljava odgovorom na pitanje kako nešto funkcioniše, dok odgovor na pitanje zašto tako funkcioniše prepušta nauci. Na slici 1 prikazana je originalna šema na kojoj se vidi da nauka pretvara novac u znanje, a da inovacije koriste znanje da bi stvorile novi kapital, odnosno profit.

Informacije koje podnosilac patentne prijave zna, ali ih ne iznosi u opisu pronalaska, danas se oznacavaju kao taj no znanje (know-how). Ove infor macije:

- ukazuju na optimalan put tehnicke realizacije pronalaska, koji je prijaviocu poznat i koji se vremenom može usavršavati; 
- omogucavaju ili olakšavaju komercijalnu eks ploataciju pronala ska;

- obezbeduju adekvatnost pronalaska u primeni drugim društvenim vrednostima i ocekivanjima (npr. ekološkim).

Dakle, bez informacija koje ostaju tajna kod podnosioca patentne prijave, industrijski interesent za korišcenje tehnic ke informacije sadržane u prijavi naj cešce ne može, ili ne može jednostavno, da primeni konkretan pronalazak u svojoj privrednoj delatnosti. Kod nas se cesto dešava da podnosilac patentne prija ve otkrije sve što zna o svom pronalasku, što je veoma štetno, kako za nje ga samog, tako i za interese naše ze mlje. Motivi koji podstaknu podnosioca prija ve da napiše sve što zna o tajnama svog pronala ska nalaze se u Zakonu o patentima [5], koji obavezuje da prezentovana prijava treba ,... da bude razumljiva struc njaku iz odredene obla sti tehnike...". Istina, veliko je umece sastaviti patentnu prijavu koja ce sadrža vati dovoljnu opisanost pronalaska, ali i neotkriven know-how. U tome su inostrani pronalazaci znatno vispreniji, jer su sve sni cinjenice da bez angažovanja patentnog zastupnika ne mogu samostalno uspešno da za vrše ovaj deo posla. Kod nas, nažalost, pronalazaci smatraju da su dovoljno kvalifikovani da napišu dobru patentnu prija vu.

Transfer tehnologije je popularan izraz za preuzimanje tude tehnologije radi nje ne praktic ne primene. Ako je rec o patentiranoj tehnologiji jasno je da takav transfer nije pravno moguc bez pristanka, tj. dozvole (licence) nosioca patenta. Otuda, le galni transfer tehnologije podrazume va kontakt zainteresovanog lica sa nosiocem patenta, radi skla panja ugovora o prometu prava za korišcenje tehnologi- je. Samo tehnic ki la ici mogu da pomisle da je tudu tehnologiju lako replikovati (imitirati) na osnovu saznanja koja se o njoj mogu dobiti istraživanjem gotovog proizvoda u kojem je ona materijalizovana. Da je to moguce, na svetu ne bi postojale razlike u tehnološkoj razvije nosti pojedinih regiona, koje se mere i vremenskim zaostajanjem od nekoliko decenija do jednog veka. Naime, veci deo tehnologija koje se danas u savremenom svetu koriste nije pod patentnom zaštitom, pa ipak ne razvije ne zemlje, odnosno njihovi privredni subjekti, nisu u stanju da te tehnologije praktic no eks ploatišu. Naime, za primenu jednog pronalaska neophodno je posedovanje tehnološkog znanja višeg nivoa od onog koje je implikovano u samom pronalasku. Otuda je za transfer tehnologije, pored upoznavanja sa samim pronalskom, potrebno steci novo znanje bez kojeg nije moguce primeniti taj pronalazak u proizvodnji i zadovoljiti sve neophodne tehnicko-ekonomske kriterijume. Vecina licencnih ugovora obuhvata patente, tajno zna nje i žigove. Licenca za patent najpre se preporucuje, jer nudi najvecu zaštitu korisniku licence, koja traje dok traje patent. Licenca za tajno znanje je manje sigurna, jer neko drugi može, nezavisno od korisnika i licencora, da otkrije informaciju ili dode do alternativnog rešenja. Period sigurnosti je kraci.

Pronalazac ne prijavljuje svoj pronalazak za patentiranje da bi ga obja vio, vec da bi dobio pravo koje ce ga zaštititi kada pronalazak inace bude morao da bude obja vlje $n$ putem privrednog iskorišcavanja. Ali, imajuci u vidu da najveci broj pronalazaka koji se prijave za patentiranje (oko 90\%) nikada ne postanu 
predmet stvarnog privrednog iskorišcavanja, izvesno je da ti pronalasci nikada ne bi bili obja vlje ni da nema patentnog sistema. Sve ga 5 do $10 \%$ tehnic kih informacija iz patentne dokumentacije dospe $\mathrm{u}$ primarnu naucno-tehnicku literaturu [3]. Posebna vrednost tih informacija, koje pruža patentni sistem, je ste njihova orijentisanost na praktic nu primenu. Takvi pronalasci, iako predstavlja ju tzv. papirnato stanje tehnike, imaju znacajnu infor macionu vrednost, jer su ne zamenljiva karika u lancu tehnološkog na pretka.

Ekonomska korist, koja se može steci iz patenta, nije u korelaciji sa vrednošcu pronalaska za društvo. Kao što je poznato, tržište cesto izdašnije nagraduje pronala ske koji su od manjeg društvenog znacaja, dok one koji su cak od epohat nog znacaja nagraduje skromnije ili ih osta vlja sasvim bez nagrade.

Preko $90 \%$ prijava pronalazaka u svetu registruju firme kao podnosioci, dok je u našoj zemlji otprilike toliki procenat individualnih pronalazaca [3]. Objašnje nje je logicno. Patentni sistem u razvijenim ze mljama je ekonomski veoma stimulativan i obavezuje poslodavca da svog radnika - pronalazaca dobro nagradi za pronalazak koji ovaj prijavi. Kod nas je praksa u vecini preduzeca potputno suprotna, zbog cega su pronalazaci destimulisani za inovacioni rad, a kada nešto i pronadu, na sve moguce nacine nastoje da izbegnu prijavu pronalaska preko svoje radne or ganizacije.

Napredak tehnike i promene u ekonomskom životu potisnuli su zna caj lic ne motivacije pronalazaca u drugi plan. Sada su dominantni organizacioni i finansijski aspekti pronalazackog delovanja. Pronalazaštvo danas pociva na timskom radu visokoobrazovanih specijalista tehnicke struke, koji, planskim is traživanjem uz izdašnu finansijsku potporu svojih poslodavaca ili drugih investitora, programirano „ciljaju“ na odredena nova tehnicka rešenja. U tom smislu, kljuc ni resursi pronalazaštva su obrazovanje, organizacija i kapital. U svetu se to dobro shvatilo pa se upravo tako i radi. Zbog neprihvatanja navedenih svetskih tokova i trendova, naš ukupni doprinos na polju pronalazaštva, u svetskim okvirima, godinama je minoran.

Naucna is traživanja danas su eliminisala tehnicki empirizam, tako da se može govoriti o cvrstoj korelaciji izmedu napretka u nauci i direktnog odraza tog napretka na tehniku i tehnologiju. Pronalasci u tehnici od polovine prošlog veka sve više se i u rastucoj meri baziraju na nauci, a u poslednje vreme postaju predmet planirane is traživacke aktivnosti. U savremenoj etapi razvoja covecanstva nauka se razvija veoma brzo, tako da se obim naucnih delatnosti udvostrucuje približno svakih 7 godina, dok se obim ostalih aktiv nosti koje su, takode, ve oma važne za razvoj covecanstva, ali nisu direktno povezane sa naukom, udvostrucuje, otprilike, sva kih 40 godina.

Projektovanje savremenog naoružanja i nje gova proizvodnja direktno su povezani sa naucnim i tehnic ko-tehnološkim napretkom u jednoj zemlji. Period od naucnog otkrica do nje gove praktic ne primene iznosio je za fotografiju 112 godina, za telefon 56 godina, za radio 35 godina, za radar 15 godina, za nukle arnu bombu 6 godina, za tranzistore 5 godina, za integrisana kola 3 godine [6]. Uocava se da se taj period stalno skracuje. 
Glavna karakteristika savremenog tehnickog napretka sastoji se u spajanju nauke i tehnike, to jest u zatvaranju lanca od fundamentalnih naucnih istraživanja, preko usmerenih primenje nih i razvojnih is traživanja, do same proizvodnje. U prošlosti, taj proces je bio, uglavnom, razdvojen. Velike mogucnosti matematickog modeliranja i br zog rešavanja komplikovanih matematic kih operacija racunarima, omogucavaju brže i pouzdanije uocavanje i analizu problema bez potrebe izvodenja skupih eks perimenata. Na taj nacin stvaraju se preduslovi za vremensko programiranje razvoja tehnike.

U da našnje vreme gube se oštre granice izmedu fundamentalnih, primenjenih i razvojnih istraživanja. Prisutna je sve veca meduzavisnost i me dusobno dopunja vanje izmedu navedenih vrsta is traživanja. Sve više je novih pronalazaka i sve je krace vreme od njihovog nastajanja do primene u praksi.

Transfer tehnike i tehnologije putem uvoza licenci, nove opreme i znanja predstavlja je dan od znacajnih puteva za smanjenje za ostalosti manje razvije nih u odnosu na razvijene zemlje. Da bi taj transfer nove tehnologije stvarno doprineo napretku zemlje, neophodno je obezbediti dalji vla stiti istraživacki i razvojni rad na novoj tehnologiji i stvarati nove kadrove.

Stanje i napredak nauke i tehnologije direktno zavise od politike zemlje u tim obla stima. Zato je potrebno izabrati jasne cilje ve i obezbediti uslove za njihovo postizanje. Do koje mere su patenti, njihova zaštita, kupovina ili prodaja trecim licima i firmama važna oblast, pokazuje primer jednog od najboljih i najcešce primenjivanih antibiotika u svetu $u$ poslednjih 20 godina. To je makrolidni antibiotik derivat eritromicina - azithromycin, otkriven u zagrebackoj „Plivi“ 1981. godine. Poznata americka firma „Pfizer“, kupila ga je za ne znatna sredstva i preimenovala u zithromax [7], da bi samo u 2000. godini ostvarila profit iznad milijardu dolara.

\section{Tehnicko-tehnološki fak tor odbrane}

Tehnic ko-tehnološki faktor postaje dominantan za postizanje strategijskog iznenadenja u pocetnom delu vodenja ratnih operacija. Danas, naravno, niko ne zanemaruje uticaj tog faktora. $\mathrm{Na}$ pocetku prošlog veka on je dovodio do vecih iznenadenja u periodu od 25 do 30 godina, a danas se taj period smanjuje na 5 do 7 godina [6]. U svakom slucaju, u vojsci se danas i u buduc nosti mora vrlo budno pratiti uticaj tehnic ko-tehnološkog faktora.

Mogucnosti za proizvodnju NVO u potpunosti zavise od mogucnosti kompletne industrije u zemlji, a narocito mašinske, he mijske i elektronske in dustrije. Prema tome, pokazatelji opšteg tehnic kotehnološkog napretka neke zemlje uje dno su i pokazatelji potencijalnih mogucnosti za proizvodnju NVO.

Naucno i tehnicko-tehnološko predvidanje sadrži niz metoda pomocu kojih se mogu izvršiti verovatne procene buduceg razvoja i širenja neke obla sti nauke i tehnike. Te metode mogu se direktno upotrebiti i u opštevojnom predvidanju, koje se može podeliti na vojnostrategijsko, vojnoekonomsko i vojnotehnicko predvidanje. Ovakva podela ne podrazumeva oštre granice, pošto su sve navedene vrste vojnog predvidanja me dusobno usko povezane [8]. 
U današnje vreme vojnotehnicko predvidanje predstavlja je dan od neosporno važnih faktora celokupnog vojnog predvidanja. Nekada su promene u naoružanju tekle sporo, a vojnotehnicka predvidanja nisu imala važnu ulogu. Medutim, kasnije su uticala na ope rativno-takticko i vojnostrategijsko predvidanje. Savremena sredstva ratne tehnike jako uticu na promene u nacinu vodenja oružane borbe. Upravo je nagli razvoj borbene tehnike, posebno avijacije i raketne tehnike sa nukle arnim ubojnim gla vama, doprineo nestajanju razlika izmedu fronta i pozadine. Danas vojnotehnic ko predvidanje postaje neophodno i je dan je od vodecih faktora $u$ opšte vojnom predvidanju.

Polazne tacke ovog predvidanja rezultat su naucnog i tehnic ko-tehnološkog progresa u poje dinim tehnic kim granama koje su najviše vezane za odredeni sistem oružja.

Inovacije u borbenoj tehnologiji cesto su bile odlucujuci faktori ishoda borbenih dejstava do pobede. U bliskoj buducnosti to ce biti sve izraženije. Tako ce komunikacije biti potpuno digitalne i umrežene. Sistemi oružja bice modularni, a informaciona tehnologija i stelt tehnologija primarni.

Smatra se da ce u periodu posle 2010. godine jedna od znacajnih obla sti biti lic na zaštita vojnika, koja podrazu-

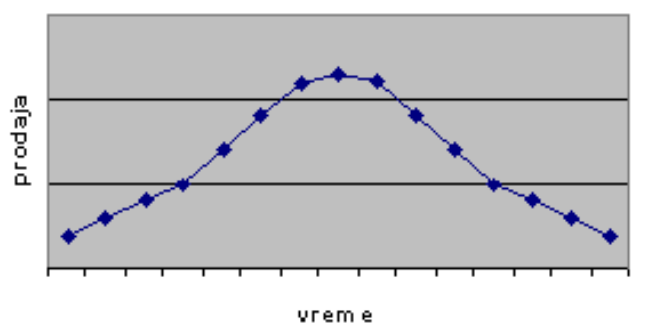

Sl. 2 - Koncept ,života“ proizvoda me va izradu uniforme napravlje ne od nekoliko slojeva [9]. Spoljni sloj bice uraden od la kog balistic kog oklopnog materijala, sa posebnom protivbalistickom zaštitom od eks plozije protivpešadijskih mina. Ode lo ce biti nevidljivo za senzore, a otporno na metke. Razni aditivi u nje mu smanjice infracrveno zracenje i time ote žati demaskiranje. Imace ugraden rashladni sistem, protkan mrežom plastic nih kapilara kroz koje struji rashladni fluid. Maskirna svojstva bice postignuta impregnisanim biodegradibilnim bojama, koje ce se same menjati u zavisnosti od okoline. Maskirnost ce biti poboljšana i ugradnjom displej tehnologije tecnih kristala u tkanini, što ce dodatno uticati na promenu boje i nijanse. Unutrašnji sloj ode la imace mikroklimatski ure daj za zagrevanje i hladenje, kao i filtrosorpcioni sloj za zaštitu od hemijskih i bioloških agensa.

Od uvodenja na tržište svaki novi proizvod ima životni ciklus koji obuhvata fazu uvodenja, rasta, zrelosti i opadanja u prodaji, što se prikazuje u obliku Gausove krive (slika 2). Taj koncept razlicito traje za razlicite proizvode - od jednog dana do više de setina godina. Uspešne firme imaju strategiju razvoja svog proizvoda, ali u toku nje govog ,života“ na tržištu preduzimaju i dodatne aktivnosti da on što duže bude profitabilan. Uvodenjem inovativnih promena na proizvodu koji se vec nalazi na tržištu, produžava se nje gov životni vek, što se najbolje vidi na slici 3 , kada Gausova kriva, kontinuiranim inoviranjem proizvoda, prelazi u niz S krivih koje poprimaju oblik „zmije u skoku“, cime se odlaže „smrt“ proiz voda na tržištu. 
Ostvaren profit od novog proizvoda (pronalaska) u direktnoj je zavisnosti od stepena zaštite [7]. Patent za proizvod (product patent) obezbeduje fir mi monopol i najviši procenat od moguceg ostvarivog profita $(90 \%)$. Patent za postupak (process patent) jeste niži stepen zaštite $\mathrm{i}$ niži je procenat moguce ostvarivog profita (oko $70 \%$ ). Zašticeni oblik proizvoda (model, uzorak), po ste penu zaštite, mogao bi da donese firmi oko $60 \%$ od moguceg profita. Proizvod zašticen samo žigom donosi oko $50 \%$ profita, dok proizvod bez zašticenog žiga donosi samo 20 do 30\% moguceg profita [7].

Vecina naših preduzeca prošla je proces privatizacije, prikazujuci svoju vrednost kapitala samo kroz materijalnu komponentu, apsolutno zanemarujuci vrednost industrijske svojine (žigove, patente, modele, uzorke, ge ografske oznake porekla, itd.) kao i organizovan rad na nje nom stvaranju. U razvijenom svetu praksa je potpuno suprotna. Tako se, na primer, od sadašnje tržišne vrednosti cuvene ame ricke firme „Majkrosoft" cak $80 \%$ odnosi na nematerijalnu vrednost (intelektualnu), a samo $20 \%$ od ukupne vrednosti na materijalnu imovinu firme.

\section{Inventivna de lat nost $u$ vojsci Srbije}

Inventivna delatnost u Vojsci Srbije regulisana je odgovarajucim uputstvom [10], u kojem se pod inovacijama podrazumevaju pronalasci, tehnicka unapredenja i konkretni predlozi znacajni za Vojsku.

Pronalaskom se smatra svaki proizvod koji sadrži tri komponente: da ima novost, inventivni nivo i privrednu pri-

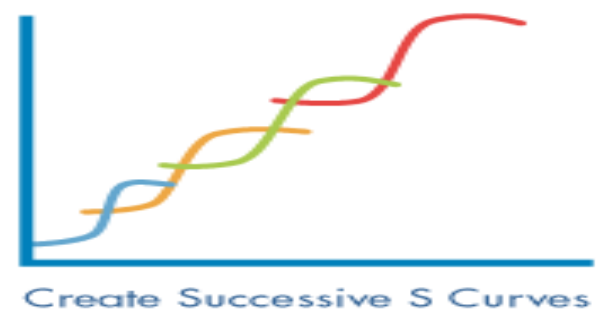

Sl. 3- Nacin produžavanja ,života “ proizvoda na tržištu

menjivost. Smatra se da je pronalazak stvoren u Vojsci ako je do nje ga došlo pri radu pronalazaca u je dinici, odnosno usta novi Vojske, na zahtev ili nalog Vojske, odnosno na osnovu ugovora zakljucenog izmedu Vojske i pronalazaca i u roku od godinu dana nakon prestanka službe u Vojsci.

Pronalasci koje Zavod za intelektualnu svojinu dostavi Vojsci na ispitivanje poverljivosti, smatraju se pronalascima stvorenim van Vojske.

Tehnic kim una predenjem smatra se svaka racionalizacija nastala stvaralackom primenom poznatih tehnic kih rešenja, sredstava i tehnoloških postupaka, kojom se u Vojsci postižu korisni efekti: poboljšanje takticko-tehnickih osobina, kvaliteta, traj nosti i pouzdanosti, kao i povecanje sigurnosti dejstva i bezbednosti upotrebe sredstava i sistema naoružanja i vojne opreme; povecanje produktivnosti rada i bolje iskorišcavanje sredstava za rad (mašine, oprema, alat, pribor, instalacije i dr.) u istraživanju, razvoju, proizvodnji, obuci i eksploataciji; uš tede radnog vremena i predmeta rada (materijal, sirovine, komponente, sastavni delovi, energija, gorivo i dr.); samostalnost u odnosu na nabavke iz inostranstva; poboljšanje radnih uslova i zaštite na radu, kao i unapredenje covekove okoline uopšte. 
Poboljšanje sadašnjeg nivoa i obima inventivne delatnosti u Vojsci može se postici samo boljim stimulativnim uslovima koji pripadaju pronala zacima, u odnosu na postojece uslove. To znaci da je neophodno promeniti postojecu zakonsku regulativu koja se odnosi na ovu oblast. To je suština funkcionisanja patentnog sistema u svim razvijenim državama i respektabilnim oružanim sna gama u sve tu.

U toku poslednjeg rata koji je voden protiv naše zemlje zapažen je veoma visok nivo inventivne sposobnosti naših ljudi. On ne bi došao do tolikog izražaja da nije bilo visokog patriotskog motiva. Taj podsticaj nije bio izazvan u miru, $\mathrm{u}$ periodu pre bombardovanja, jer nije bio dovoljno stimulisan. U miru najveci podsticaj cini finansijski momenat i društveno priznanje koje inovator dobija za svoj uspešni angažman. Medutim, pored motiva, za uspeh su neophodni i povoljni uslovi za stvaralaštvo. Tesla verovatno ne bi uradio ni deseti deo svojih pronalazaka da je stvarao u našoj ze mlji.

U Drugom svetskom ratu nacisti su imali tzv. Himler-Šperov zakon o patentima koji je bio izuzetno podsticajan za inovatore [11]. Zahvaljujuci nje mu, u uslovima vodenja žestokih oružanih borbi protiv saveznika na raznim frontovima, Nemci su pronalazili nova oružja (npr. nove bojne otrove, rakete, tenkove, itd.), ali su isto tako stvarali nove epohat ne pronalaske i tehnologije civilnog karaktera, koji su održavali njihovu privredu izuzetno moc nom i žila vom. Posle završetka rata, u uslovima privrednog sloma i potpuno razorene infrastrukture zemlje, Nemci su uvideli da Himler-Špe rov zakon treba samo u ideološkom smislu procistiti, ali u svojoj osnovi zadržati nepromenje nim. To je je dan od razloga ubrzanog oporavka i nezadrživog rasta posleratne nemacke privrede [11]. Norveška i Austrija su na osnovu nemackog zakona uradile svoje nacionalne zakone o patentima. Danas su sve tri pomenute zemlje medu najuspešnijima u svetu u pogle du inovativnog doprinosa rastu i stabilnosti njihovih privreda.

Kada se analiziraju, široj javnosti dostupni, podaci o sadržaju bilateralnih meduarmijskih sporazuma o vojnoj saradnji naše vojske, na rocito sa tehnološ ki opremlje nijim vojskama, uocava se da su strane armije za interesovane za naša inovaciona odbrambena tehnicka rešenja primenje na $\mathrm{u}$ toku bombardovanja zemlje, a pre sve ga u obla sti protivvazdušne odbrane i medicinska is kustva u saniranju posle dica ranja vanja naših vojnika (primenje ne tehnike, materijali, me tode, postignuti rezultati, itd.). Neposredno nakon agresije NATO-a govorilo se da je naš najbolji izvozni brend vojnik i nje govo oružje, ali to nije is korišceno na pravi nacin i u dovoljnoj meri.

U na šoj zemlji se poslednjih godina Zavodu za intelektualnu svojinu u proseku prija vi oko 1000 pronalazaka na godišnjem nivou. Koji od njih su od vitalnog znacaja za privredu zemlje, a koji su beznacajni? Na ovo pitanje Zavod za intelektualnu svojinu ne može da pruži adekvatan odgovor, jer ne raspolaže neophodnim strucnim i laboratorijskim resursima iz tehnickih obla sti koje su zastuplje ne u pronalascima, mada to ni nije njihov zadatak. Oni su zaduženi da formalno-pravno obraduju patentne prija ve $\mathrm{i}$ da pretražuju patentne podatke, tj. medu- 
narodni i domaci ,rešerš“‘. U na šoj zemlji još uvek ne ma kompe tentne ustanove koja bi mogla da vrednuje stvarni kvalitet pronalaska, odnosno podnetih patentnih prija va sa stanovišta znacaja pronalaska koji opisuju. Zbog toga cesto dolazi do pogrešnih procena o vrednosti pojedinih pronalazaka, što ponekad može da predstavlja gubitak od strateškog znacaja za privredu zemlje ili nje nu odbranu.

Dakle, pri razmatranju i oceni pronalazaka treba biti veoma strucan, dalekovid $\mathrm{u}$ naucno-struc nom smislu, i posedovati niz multidicsiplinarnih sposobnosti da bi ekspertiza bila objektivna. To da nas mogu da urade samo grupe eksperata iz razlicitih obla sti, a nikako poje dinac. U proteklom periodu, od formiranja Zavoda do danas, broj pronalazaka koji su ostali mrtvo slo vo na papiru je impozantan i predstavlja ,mrtav kapital". Za nje govo pokretanje, oplemenjivanje tj. doradu i plasiranje zainteresovanim partnerima u zemlji i inostranstvu, neophodna je koncepcija, tj. dobro utemeljen proje kat. Slic na konstatacija važi i za Vojni odsek za patente. Nedavno promovisan Nacionalni investicioni plan, koji je uraden po uzoru na irski model, nudi mogucnost finansiranja modernizacije NVO, što se najuspešnije može izvesti primenom inovacionog koncepta.

U Sovjetskom Savezu je odmah posle Drugog svetskog rata, u oblast inovacione delatnosti uvedena i jedna nova metodologija i tehnika rešavanja inventivnih proble ma, poznata pod imenom TRIZ (Te orija rešava nja inventiv nih proble ma) $[12,13]$. Tvorac TRIZ-a je Henrih S. Altšuler, koji je kao porucnik bio zaposlen u Patentnom birou Sovjetske mornarice za is pitivanje pa tenata. Nje gov zadatak bio je da pomaže naucnicima i inženjerima u izradi patenata, tako da je bio neposredno ukljucen u taj kreativni posao. Proucivši skoro pola miliona pa tenata, on je uocio osnovne zakonitosti i karakteristike koje opisuju bilo koji novi pronalazak. Altšuler je proucavanjem pronala zaka identifikovao 39 standardnih parametara i 40 zajednickih inventivnih principa za rešavanje protiv recnosti pronalaska, na osnovu kojih je razvio svoju teoriju u procesu rešavanja inventivnih proble ma. TRIZ je skoro 45 godina tretiran kao vrhunska sovjetska tajna, sve dok u doba perestrojke i vla davine Gorbacova nije ,prebacen“ na Zapad. Upravo zahvaljujuci TRIZ-u Rusi su skoro 50 godina uspevali, uz ne uporedivo niža finansijska ula ganja, da us pešno pariraju Amerikancima u obla stima inovativnog razvoja NVO i pri osvajanju kosmosa. Zanimljivo je da Albert Ajnštajn, je dan od najvecih naucnika svih vremena, u doba svoje najvece kreativne moci, radeci u švajcarskom patentnom zavodu, nije uocio zakonitosti do kojih je došao Altšuler. Zbog ge nijalnog doprinosa teoriji rešavanja inventivnih problema, Altšulera danas s pravom mnogi smatraju jednim od najvecih umova 20. veka.

Danas je TRIZ sistematska me todologija rešavanja inventivnih proble ma, poznata u celom svetu [13]. Od 1996. godine TRIZ se nalazi i u SAD. Americki štab TRIZ-a smešten je u Silikonskoj dolini (Kalifornija), trgovackom centru visoke tehnologije, a usvojen je u Japanu, V. Britaniji i mnogim drugim tehnološki najrazvije nijim zemlja ma. Brojne zemlje u sve tu traže od eks perata TRIZ-a da im obuce inženjerski kadar, po njihovim metodama. Neke od svetski poznatih kompanija, kao što su Gla xo, Gillette, 
Rolls-Royce, Intel, Volvo, United Utilities, Mars, Exxon, itd., takode primenjuju me tode TRIZ-a. Strucnjaci TRIZ-a izradili su softver za primenu svojih me toda, ali on sam nije dovoljan za koriš cenje u praksi. TRIZ nudi obuku preko Interneta. Jedan od nje govih glavnih ciljeva je tehnicka podrška i pomoc zainteresovanim licima da naprave visoki profit sa novim proizvodom i ubrzaju tehnološki napredak svoje firme i zemlje. TRIZ rešenja direktno se manifestuju u poboljšanju proizvoda i smanje nju cene proizvodnje. Danas ima softversku bazu podataka koja obuhvata preko 3 miliona najjacih svetskih patenata.

U SAD postoji visoko razvijen sistem raznih asocijacija i posrednika izmedu pronalazaca i tržišta. Postoji mnoštvo firmi koje se bave raznim segmentima ove delatnosti i na tome zasnivaju biznis.

U doba velike ekonomske krize u Sjedinjenim Americ kim Državama, 1929. godine, ta dašnji predsednik Ruzvelt rekao je da su tehnologije kljuc razvoja ekonomije, a kljuc tehnologije - patenti. Tadašnji „New deal“" projekat napravio je od Amerike ekonomsku ve le silu.

Vecina proizvodnih preduzeca i drugih organizacija koje sacinja vaju vojnoindustrijski kompleks na teritoriji Srbije, dospela su u poziciju da ne mogu da angažuju deo svojih proizvodnih kapaciteta zbog smanje nih potreba Vojske za sredstvima NVO i reduciranih izvoznih moguc nosti koje su usle dile zbog zastarelosti raspoloživih tehnologija i neusaglašenosti sa standardima i propisima EU (problem harmonizacije propisa). Kao posledica takvog stanja pojavio se pro- blem tehnološkog viš ka ka drova, ne angažovanosti proiz vodnih i razvojnih potencijala preduzeca i ustanova, niske zarade zaposle nih lica i dr. Na osnovu analiziranih is kustava, primenje nih $\mathrm{u}$ razlicitim zemljama, ocigledno je da inovacioni koncept, zastupljen u proizvodnji, može da predstavlja nadu za novi privredni oporavak.

Dakle, za našu privredu i odbrambe$\mathrm{nu}$ industriju, spasonosnu formulu treba tražiti u politici novih (inovativnih) proizvoda ili grupe proizvoda, a ne u proizvodnim granama ili grupacijama, kao što je to bio slucaj do sada. Pogoršanje strukture naše privrede uocava se u padu izvoznih mogucnosti, jer je izostala konkurentnost proizvoda, koja se na svetskom tržištu postiže nje govom inovativnošcu. Unazad deset godina nije zabeleže no da je neko naše preduzece izašlo na medunarodno tržište sa originalnim proizvodom.

\section{Zakljucak}

Vojnoindustrijski kompleks je specifican zbog vrste proizvodnje kojom se bavi, što ima i niz prednosti u odnosu na ci vilni segment industrije: dostignuti nivo sistema kvaliteta prisutan u proizvodnji, dobra or ganizacija rada, visoka odgovornost u poslovanju, itd. Po nacinu rada $i$ osposoblje nosti radnika, vojnoindustrijski kompleks predstavlja jednu od najstruc nijih grupacija zaposlenih lica u domacoj privredi. Njihovo otpuštanje predstavlja dugorocni ekonomski gubitak za privredu Srbije. Ipak, može se izbeci ili donekle ubla žiti ukoliko se radnici angažuju na ci vilnim inovacionim programima. 
Poznato je da su inovacioni programi kroz istoriju bili pokretac privrednog oporavka, kako na makropla nu (npr. programi državnog oporavka SAD, Irske, Japana), tako i na mikropla nu (npr. pojedina preduzeca - Simens, Samsung, Soni, itd.).

U radu je ukazano na znacaj intelektualne svojine u društvu, a narocito uticaj patenata na tehnicko-tehnološki razvoj neke zemlje. Istaknut je i znacaj inovacionog rada u obla sti odbrambene tehnologije na ukupnu borbenu sposobnost savremene armije i ukazano na potrebu drugacijeg organizovanja u obla sti inovacionog stvaralaštva na polju odbrambenih tehnologija, ne go što je to bio slucaj u prethodnom periodu.

U Vojsci Srbije postoje neiskorišceni inventivni potencijali koje je moguce pokrenuti reformskim zahvatima $\mathrm{u}$ toj oblasti, pocev od promene normativnopravne regulative, narocito $\mathrm{u}$ delu koji se odnosi na oblast podsticaja stimulacije inovatora, preko us postavlja nja novog modela organizovanja u kojem je uspo- stavlje na tesna korelacija izmedu nauke, pronalazaštva i proizvodnje. TRIZ se sma tra najpogodnijom naucnom metodologijom u obla sti inovacionog stvaralaštva, koju je neophodno imple mentirati u našu praksu.

Literatura:

[1] Prava intelektual ne svojine i svet ska trgovinska organizacija, USAID Projekat za pri stup SRJ Svetskoj trgovinskoj organizaciji.

[2] Besarovic, V.: Intelektualna svojina, Centar za publikaci je, Pravni fa kultet, Beograd, 2005.

[3] Markovic, S.: Patentno pravo, Nomos, Beograd, 1997.

[4] Maric, V.: Forma žiga, Fakultet za poslovno pravo, Beograd, 2003.

[5] Zakon o patentima, Službeni list SCG, 32/2004.

[6] Rendulic, Z.: Naucnotehnicki progres i naoružanje, VIZ, Beograd, 1981.

[7] Jovanovic, S.: Pronalazacka aktivnost u farmaceutskoj industriji, Savezni zavod za intelektual nu svojinu, Beograd, 1996.

[8] Cujev, J. V., Mihajlov, J. B.: Prognoziranje u Vojsci, VIZ, Beograd, 1980.

[9] Alexander D.: Tomorrow's soldier, Avon Books, New York, 1999

[10] Jovic, I.: Uputstvo o inventivnoj delatnosti u VJ, VIZ, 2001.

[11] Advanced Successful Technology Licensing (STL) Workshop, Belgrade, 2006.

[12] A???????, ?. ?: ????????? ??? ?????? ?????

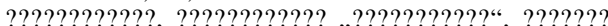
2-?, ???????????,2006

[13] Altshuller, G., Shulyak, L.: 40 Principles: TRIZ Keys to Technical Innovation, Technical Innovation Center, Worcester, MA, 2001. 